\title{
Correlation of clinical, biochemical and radiological characteristics with histopathology of ovarian masses: hospital based descriptive study
}

\author{
Poonam Laul $^{1}$, Urvashi Miglani ${ }^{1 *}$, Atima Srivstava ${ }^{1}$, Neelam Sood ${ }^{2}$, Sanjeev Miglani ${ }^{3}$
}

\begin{abstract}
${ }^{1}$ Department of Obstetrics and Gynaecology, ${ }^{2}$ Department of Pathology, DDU Hospital, New Delhi, India
${ }^{3}$ Department of Medicine, Gangaram Hospital, New Delhi, India
\end{abstract}

\author{
Received: 30 July 2020 \\ Revised: 18 September 2020 \\ Accepted: 21 September 2020 \\ *Correspondence: \\ Dr. Urvashi Miglani, \\ E-mail: urvashim513@gmail.com
}

Copyright: (C) the author(s), publisher and licensee Medip Academy. This is an open-access article distributed under the terms of the Creative Commons Attribution Non-Commercial License, which permits unrestricted non-commercial use, distribution, and reproduction in any medium, provided the original work is properly cited.

\begin{abstract}
Background: Ovarian cancer is an important cause of morbidity and mortality in the middle aged women. A systematic study of all ovarian tumours encountered in a large institute over a period of years is more likely to produce a significant amount of useful data regarding the clinical manifestations, the incidence of various types of ovarian tumours and the type of treatment offered. In this study we correlate various clinical presentations, ultrasound features, and various tumour marker levels with histopathology of ovarian masses.

Methods: The study was conducted in the department of obstetrics and gynaecology in collaboration with department of radiology and pathology and lab medicine, Deen Dayal Upadhyay hospital from April 2015 to December 2016.

Results: In the present study, 97 ovarian masses have been operated out of total 708 gynaecological surgeries in the obstetrics and gynaecology department of Deen Dayal Upadhyay hospital over the stipulated period. Prevalence of ovarian masses was $13.7 \%$. Most of the ovarian masses were prevalent in the reproductive age group i.e. 21-40 years of age group in the present study though malignant masses were commonest in post-menopausal age group in the present study. 2 out 11 malignant ovarian masses were in the age group of 10-20 years which were dysgerminoma and immature teratoma respectively. Intra-operative findings like presence of mural nodule, haemorrhage and necrosis, ascites, papillary excrescences and omental caking were also found to have strong correlation with malignancy.

Conclusions: A detailed preoperative workup and a simple tool loke RMI can differentiate between benign and malignant masses pre-operatively especially in post-menopausal women.
\end{abstract}

Keywords: Ovarian tumours, Risk of malignancy index, Benign ovarian masses

\section{INTRODUCTION}

Ovarian cancer is an important cause of morbidity and mortality in the middle aged women. Ovarian cancer is the ninth most common cancer and the fifth leading cause of cancer death. ${ }^{1}$ Although many physicians are concerned about the failure to detect an ovarian malignancy, it is important to realize that the majority of adnexal masses, particularly in premenopausal women, are benign.

Ovarian tumours have varying modes of presentation. Benign ovarian masses present at an early age compared to malignant tumours which present in 5th decade. Risk of malignant ovarian masses increases with age, low parity and infertility. Symptoms are ambiguous and often misdiagnosed, so majority of patients are only identified in the advanced stage of disease. Ovarian cancer is therefore often referred to as the 'silent killer' ${ }^{2}$

A systematic study of all ovarian tumours encountered in a large institute over a period of years is more likely to produce a significant amount of useful data regarding the clinical manifestations, the incidence of various types of ovarian tumours and the type of treatment offered. In this study we correlate various clinical presentations, 
ultrasound features, and various tumour marker levels with histopathology of ovarian masses. This data can be utilized for the purpose of suggesting ways and means of early detection of ovarian neoplasms and also for a better therapeutic approach to the problem.

\section{METHODS}

This was a prospective observational study conducted on patients with ovarian masses at the department of obstetrics and gynaecology, Deen Dayal Upadhyay hospital, a referral centre in West Delhi from April 2015 to December 2016.

\section{Inclusion criteria}

In the current study inclusion criteria was all cases of ovarian masses which were surgically managed in department of obstetrics and gynaecology of Deen Dayal Upadhyay hospital, New Delhi.

\section{Exclusion criteria}

In the current study exclusion criteria were all cases of ovarian masses managed conservatively and all nonovarian adnexal masses.

\section{Procedure}

A predesigned proforma was used to collect data from cases of ovarian masses admitted in obstetrics and gynaecology department of Deen Dayal Upadhyay hospital regarding clinical symptoms, demography, family history and contraceptive history. A detailed general examination and systemic examination was done to detect any associated systemic illness. Apart from

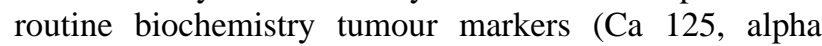
fetoprotein, lactate dehydrogenase) ultrasonography was done, and risk of malignancy index (RMI) was calculated.

Histopathological examination of the specimens was conducted by the department of pathology of Deen Dayal Upadhyay hospital following appropriate staining (haematoxylin and eosin staining). The histopathological reports (HPR) were based on WHO classification of ovarian tumours. Data obtained was statistically analysed to obtain significant correlation.

\section{Calculation of risk of malignancy score (RMI)}

Risk of malignancy index 2 (RMI 2) as defined by Tingulstad et al was calculated. ${ }^{3}$ Adnexal masses were evaluated for sonographic morphological criteria; bilaterality, solid areas, multilocularity, ascites, and metastases. Ultrasound score was assigned as $U=1$ if 0 or 1 criteria were fulfilled and ultrasound score $U=4$ if 2 or more criteria were fulfilled and total score was calculated. Menopausal status was noted. Menopause was defined as one or more year of amenorrhea or women who had undergone hysterectomy. Menopausal score was assigned $M=1$ if premenopausal and $M=4$ if postmenopausal. RMI 2 was calculated as a product of UxMxCA 125. Cut off level of 200 was set to differentiate between benign and malignant mass. USG findings included; locularity, presence of solid areas, ascites, metastasis and laterality of lesion.

\section{Statistical analysis}

Descriptive statistics was analysed with SPSS version 17.0 software. Continuous variables were presented as mean SD or median if the data is skewed. Categorical variables will be expressed as frequencies and percentages.

Nominal categorical data between the groups were compared using Chi-square test or Fisher's exact test as appropriate.

The comparison of normally distributed continuous variables between the groups was performed using Student $\mathrm{t}$ test otherwise Mann Whitney $\mathrm{U}$ test was done.For all statistical tests, a $\mathrm{p}$ value less than 0.05 was taken to indicate a significant difference.

\section{RESULTS}

The current study was a prospective observational study carried out in 97 cases of ovarian masses who were admitted in the Obstetrics and Gynaecology department through OPD and emergency.

\section{Demographic profile}

$75(77.3 \%)$ of the women in the present study group were in the reproductive (21-40 years) age group. Mean age of the study subjects was 31 years. $6(54.5 \%)$ cases out of 11 malignant cases were $>60$ years of age. 87 of patients in the present study $(89.7 \%)$ had normal BMI.

Out of total 97 patients, $22(22.6 \%)$ were nulliparous and $75(77.3 \%)$ patients were multiparous. $83(85.6 \%)$ were premenopausal and 14 cases $(14.4 \%)$ were postmenopausal. Two patients $(2.2 \%)$ had history of ovulation induction, $6(20.0 \%)$ had history of sterilization, one patient had history of intake of oral contraceptive pills. The frequency distribution of the various clinical features is depicted in (Table 1). Out of total 97 cases, 86(88.7\%) subjects had benign ovarian masses while $11(11.3 \%)$ had malignant ovarian masses on histopathological examination. Frequency distribution of various adnexal masses in the study population is depicted in (Table 2). 74 (83\%) patients, out of patients, with benign ovarian masses were in the age group of 2140 years. $6(54.5 \%)$ out of total 11 subjects with malignant ovarian masses in the present study were $>60$ years of age. Maximum number of subjects both in benign $(90.7 \%)$ or malignant group $(81.8 \%)$ of ovarian masses, had normal BMI in the present study. $6(54.5 \%)$ 
of patients with malignant masses and8 $(9.3 \%)$ of those with benign ovarian masses were postmenopausal. $(p<0.001)$. Out of 97 cases, one patient with malignant and one patient with benign ovarian mass on histopathology had history of ovulation induction and the correlation was statistically not significant. 6 out of total 97 patients had history of sterilization, all of which were benign on histopathological examination and the correlation was statistically not significant. Only one patient out of 97 patients with ovarian masses had history of oral contraceptive pill intake in the present study, which on histopathology came as benign Brenner tumour. $P$ value was statistically insignificant $(p>1.000)$. The frequency distribution of size of adnexal mass among benign and malignant tumours is depicted in (Table 3 ).

None of the patients out of total 97 patients had raised AFP levels.All the 86 subjects with benign masses had normal AFP levels and Ca125 less than $35 \mathrm{U} / \mathrm{ml}$. Among the malignant ovarian masses, all had normal AFP value, but 7 out 11 had Ca125 level more than $35 \mathrm{U} / \mathrm{ml}$ $(\mathrm{p}<0.001)$.

Table 1: Frequency distribution according to clinical features.

\begin{tabular}{|ll|}
\hline Clinical features & N $(\%)$ \\
\hline Pain abdomen & $43(44.3)$ \\
\hline Lump abdomen & $34(35.1)$ \\
\hline Menstrual complaints & $8(8.2)$ \\
\hline Infertility & $12(12.4)$ \\
\hline Pressure symptoms & $25(25.8)$ \\
\hline Asymptomatic /non-specific & $24(24.7)$ \\
\hline
\end{tabular}

\section{Radiological features}

Laterality vs. histopathology; out of total 11 malignant ovarian masses, $8(72.7 \%)$ were unilateral on USG while $3(27.3 \%)$ were bilateral. Amongst 86 benign masses, 4 $(4.7 \%)$ were bilateral. Bilaterality had good statistical correlation with malignant ovarian masses $(\mathrm{p}<0.001)$.

Septations vs. histopathology; amongst 11 malignant ovarian masses patients out of total 97 subjects, 9 $(81.8 \%)$ had thick, irregular septa on USG findings.5 out of total 88 patients with benign ovarian masses had thin septa on ultrasonography. Presence of thick, irregular septa on USG had good statistical correlation $\mathrm{p}<0.001$.

Solid areas vs. histopathology; solid areas were present in all the malignant cases and in $14(16.3 \%)$ of the benign ovarian masses.

Ascites vs. histopathology; out of total 11 cases with malignant ovarian masses, $4(36.3 \%)$ had ascites on ultrasonography. None of the benign masses had any evidence of ascites on USG.Presence of ascites had good statistical correlation in the present study, $\mathrm{p}<0.001$. 6 out of the 11 malignant cases had RMI more than 200 and all the benign tumours had RMI <200 ( $<<0.001)$.

Table 2: Frequency distribution of various adnexal masses in the study population.

\begin{tabular}{|lll|}
\hline $\begin{array}{l}\text { Histopathology } \\
\text { Benign serous } \\
\text { cystadenoma }\end{array}$ & 26 & 26.8 \\
\hline $\begin{array}{l}\text { Benign brenner's } \\
\text { tumour of ovary }\end{array}$ & 2 & 2.1 \\
\hline $\begin{array}{l}\text { Benign mucinous } \\
\text { cystadenoma }\end{array}$ & 3 & 3.1 \\
\hline $\begin{array}{l}\text { Benign serous } \\
\text { cystadenofibroma }\end{array}$ & 2 & 2.1 \\
\hline Corpus luteal cyst & 5 & 5.2 \\
\hline Mature cystic teratoma & 15 & 15.5 \\
\hline Dysgerminoma & 1 & 1.0 \\
\hline Endometriotic cyst & 13 & 13.4 \\
\hline Follicular cyst & 2 & 2.1 \\
\hline Fibroma of ovary & 1 & 1.0 \\
\hline Fimbrial cyst & 1 & 1.0 \\
\hline Haemorrhagic cyst & 7 & 7.2 \\
\hline Immature teratoma & 1 & 1.0 \\
\hline $\begin{array}{l}\text { Mucinous } \\
\text { cystadenocarcinoma }\end{array}$ & 1 & 1.0 \\
\hline $\begin{array}{l}\text { Papillary serous } \\
\text { cystadenocarcinoma } \\
\text { with metastasis }\end{array}$ & 2 & 1.0 \\
\hline Para ovarian cyst & 5 & 3.1 \\
\hline $\begin{array}{l}\text { Serous } \\
\text { cystadenocarcinoma }\end{array}$ & 1 & 100.0 \\
\hline $\begin{array}{l}\text { Serous } \\
\text { cystadenocarcinoma } \\
\text { with metastasis }\end{array}$ & 3 & 2.0 \\
\hline $\begin{array}{l}\text { Serous } \\
\text { cystadenocarcinoma } \\
\text { with mucinous features }\end{array}$ & 1 & 5.2 \\
\hline $\begin{array}{l}\text { Serous papillary } \\
\text { cystadenocarcinoma }\end{array}$ & 1 & 1.0 \\
\hline Struma ovarii & 97 \\
\hline Torsion ovary & & Percentage \\
\hline Total & 1 & 2.0 \\
\hline
\end{tabular}

Intra-operative features suggestive of malignancy $v / s$ histopathology

Out of total 11 subjects with malignant masses, 10 had haemorrhage and necrotic areas on cut section intraoperatively. 6 patients out of 11 malignant ovarian masses had omental caking on intra-operative finding. Mural nodule, ascites and papillary excrescences were seen in 3, 4 and 3 patients with malignant ovarian masses peroperatively. All the intra-operative findings were statistically significant for the diagnosis of malignant ovarian mass. 
Table 3: Frequency distribution of size of adnexal mass among benign and malignant tumours.

\begin{tabular}{|c|c|c|c|c|c|c|}
\hline \multirow{3}{*}{ Size of adenexal mass } & \multicolumn{4}{|c|}{ Histopathology } & \multirow{3}{*}{$\begin{array}{l}\text { Total } \\
\text { cases }\end{array}$} & \multirow{3}{*}{ p value } \\
\hline & \multicolumn{2}{|l|}{ Benign } & \multicolumn{2}{|l|}{ Malignant } & & \\
\hline & Frequency & $\%$ & Frequency & $\%$ & & \\
\hline$<10 \mathrm{~cm}$ & 66 & 76.7 & 1 & 9.1 & 67 & \multirow{3}{*}{$<0.001$} \\
\hline$>10 \mathrm{~cm}$ & 20 & 23.3 & 10 & 90.9 & 30 & \\
\hline Total & 86 & 100 & 11 & 100 & 97 & \\
\hline
\end{tabular}

\section{DISCUSSION}

In the present study out of total 97 patients, $27(27.8 \%)$ of the ovarian masses were non-neoplastic, 59 (60.8\%) were benign and remaining $11(11.3 \%)$ were malignant. In the present study, benign ovarian masses were commonest followed by non-neoplastic masses and malignant masses. This finding is in concordance with the results of Zahra et al. ${ }^{4}$ The percentage of malignant tumours found in the studies of Rashmi et al is higher than the present study probably because our hospital caters to a lower socio-economic stratum with less education and health awareness. ${ }^{5}$ Consequently, many of the patients reached the healthcare facilities in advanced stages and were referred for debulking after neo-adjuvant chemotherapy.

One of the subjects with a pre-operative diagnosis of malignant ovarian tumour turned out to be a uterine tumour intra-operatively, final histopathological diagnosis was sarcomatous tumour with hematometra ,so was excluded from the study Among the 11 patients with ovarian neoplastic masses, serous cystadenocarcinoma was the commonest diagnosis $63.6 \%$, followed by one case of dysgerminoma and one case of immature teratoma. Comparison of histopathological pattern of various ovarian masses with other studies is depicted in (Table 4). ${ }^{6,7}$

Table 4: Comparison of histopathological pattern of various ovarian masses.

\begin{tabular}{|c|c|c|c|c|}
\hline Study & Present study & Avani et al $^{6}$ & Zahra et $a^{3}$ & Kanthikar et al $^{7}$ \\
\hline $\begin{array}{l}\text { M/C non- } \\
\text { neoplastic }\end{array}$ & Endometriotic cyst & Serous cyst & Endometriotic cyst & Serous cyst \\
\hline M/C benign & $\begin{array}{l}\text { Benign serous } \\
\text { cystadenoma }\end{array}$ & $\begin{array}{l}\text { Benign serous } \\
\text { cystadenoma }\end{array}$ & $\begin{array}{l}\text { Benign serous } \\
\text { cystadenoma }\end{array}$ & $\begin{array}{l}\text { Benign serous } \\
\text { cystadenoma }\end{array}$ \\
\hline $\begin{array}{l}\mathrm{M} / \mathrm{C} \\
\text { malignant }\end{array}$ & $\begin{array}{l}\text { Serous } \\
\text { cystadenocarcinoma }\end{array}$ & $\begin{array}{l}\text { Serous } \\
\text { cystadenocarcinoma }\end{array}$ & $\begin{array}{l}\text { Serous } \\
\text { cystadenocarcinoma }\end{array}$ & $\begin{array}{l}\text { Serous } \\
\text { cystadenocarcinoma }\end{array}$ \\
\hline
\end{tabular}

In the present study most of the patients belonged to middle lower middle socioeconomic status according to Kuppuswamy classification. This finding may be attributed to the fact that most of the patients visiting our hospital belong to lower socioeconomic strata. There is a need to thoroughly characterize the association between socioeconomic status and ovarian masses as no studies are available to show significant correlation.

Oral contraceptive intake and tubal ligation have a proven role in preventing ovarian tumours. ${ }^{8}$ Very few patients in the present study had this history. This may be attributed to the fact that most of the patients coming to our hospital belong to lower socio-economic status, and often hesitate to seek medical help for contraceptive measures due to logistic or social reasons. History of ovulation induction is considered to be a risk factor for borderline tumours. ${ }^{9}$ In the present study 2 patients had history of ovulation induction. Among the two, one case was diagnosed with mature cystic teratoma and the other with borderline cystadenocarcinoma with minimal invasion on histopathology. The presenting features of majority of the patients in the present study (pelvic pain, pressure symptoms non-specific complaints) were in concordance with that reported in literature. ${ }^{5,7}$ This further reiterates the ACOG guidelines which state that the patient and her obstetrician-gynaecologist should maintain an appropriate level of suspicion when potentially relevant signs and symptoms of ovarian cancer are present i.e. Women with more than 12 days per month of new onset (less than 12 months' duration) symptoms, including an increase in abdominal size or bloating, pelvic or abdominal pain, or difficulty eating or feeling full quickly. Such patients have increased odds of having ovarian cancer compared with women without these symptoms. ${ }^{10}$

In the present study, maximum number of patients i.e. 73 $(85 \%)$ with benign masses were in the age group of 21-40 years i.e. reproductive age group. Incidence of malignant masses in women more than 60 years of age was significantly higher $(\mathrm{p}<0.001)$ than younger women.

This was in agreement with study done by Rashmi et al who found that benign tumours were common in the reproductive age group between 21-50 years with peak incidence of 13 cases $(30.2 \%)$ in the age group of 31-40 years. ${ }^{5}$ Malignant tumours were common in age group of 51-60 years and above with peak incidence of 10 cases 
$(43.4 \%)$ in 51-60 years of age. Borderline tumours were common in 41-50 years of age.

In the present study maximum $66(76.7 \%)$ patients with benign masses had size $<10 \mathrm{cms}$ and $20(23.3 \%)$ patients had size of mass $>10 \mathrm{cms}$. Out of 11 patients with malignant masses 10 were of size more than $10 \mathrm{cms}$, which was statistically significant with $\mathrm{p}<0.001$. This was comparable with the study by Wills et al who analysed that while most of the masses less than $5 \mathrm{~cm}$ were nonneoplastic lesions, the larger ones $(>15 \mathrm{~cm})$ belonged to the mucinous and endometriotic category. ${ }^{11}$

In the present study, $96.5 \%$ of benign cases had Ca125 level below $35 \mathrm{IU} / \mathrm{ml}$. $77.8 \%$ of malignant cases had elevated $\mathrm{Ca} 125$ level. $97.6 \%$ patients with benign masses had normal levels of LDH while $2.3 \%$ had elevated levels of $\mathrm{LDH}$, which included 2 cases of mature cystic teratoma. In malignant ovarian masses $36.4 \%$ had elevated LDH levels. This is in concordance with a recent study by Deepa et al who found a sensitivity of $57.1 \%$, specificity of $84.1 \%$, accuracy of $78.7 \%$, positive predictive values of $47.1 \%$ and negative predictive values of $88.8 \%$ for LDH in malignant ovarian tumour.$^{12}$

These data indicate that each parameter is useful as a tumour marker for the specific histological type of ovarian tumour; $\mathrm{Ca} 125$ for non-mucinous epithelial carcinoma, CEA for mucinous tumour and Krukenberg tumour, AFP for yolk sac tumour, LDH and LDH isoenzymes for dysgerminoma and other solid germ cell tumours. In addition, preoperative diagnosis of histological types of ovarian tumours may be possible by combining these tumour markers.

All the patients with benign ovarian masses had RMI $<200$. RMI had good correlation with malignancy in the present study as has also been shown in various studies done on this subject. ${ }^{13}$

Majority $82(95.3 \%)$ patients with benign masses were unilateral. The incidence of laterality was in accordance with similar study done by Kanthikar et al who found that $78.18 \%$ of unilateral masses, all of which were benign. ${ }^{7}$ Presence of solid areas, thick and irregular septa and ascites were found to be statistically significant for diagnosis of malignancy on the basis of USG features in the present study.

This was similar to Kanthikar et al who found that $66.67 \%$ cystic masses were benign on histopathology, $13.3 \%$ of benign masses were solid while malignancy was diagnosed in $42.85 \%$ of solid masses. ${ }^{7}$ Intraoperatively haemorrhage, necrosis, mural nodule, papillary excrescences and omental caking were significantly associated with diagnosis of malignancy. Imaging findings that are suggestive of malignant tumours include a thick, irregular wall; thick septa; papillary projections; and a large soft-tissue component with necrosis. Ancillary findings of pelvic organ invasion, implants (peritoneal, omental, mesenteric), ascites, and adenopathy increase diagnostic confidence for malignancy. Omental caking was present in 6 out of 9 malignant cases in the present study, which is in agreement with study done by Mamlouk et al, who found that omental cakes typically are associated with epithelial ovarian carcinoma. ${ }^{14}$

\section{CONCLUSION}

It can be concluded from current study that, benign ovarian masses were commonest followed by nonneoplastic masses and malignant masses. Based on histopathology, most common neoplasm was surface epithelial tumor. Ovarian masses were predominantly common in pre-menopausal age group, however malignant tumors were more common in postmenopausal age group. Ovarian tumors have varying mode of presentation. Abdominal pain was the most common presentation followed by mass per abdomen and pressure symptoms. Larger size masses were generally malignant.

\section{Recommendations}

A detailed pre-operative work-up (detailed history, general physical examination, tumour markers and ultrasound findings) is imperative for all cases of ovarian masses. Despite availability extensive radiological investigations, the importance of simple tool like RMI cannot be under-estimated to differentiate between benign and malignant masses pre-operatively especially in post-menopausal women. Intra-operative findings like mural nodule and papillary excrescences help the clinician in predicting the nature of tumour.

\section{Funding: No funding sources}

Conflict of interest: None declared

Ethical approval: The study was approved by the Institutional Ethics Committee

\section{REFERENCES}

1. United States cancer statistics: 1999-2013, incidence and mortality web-based report. Available at: https://wonder.cdc.gov/wonder/help/CancerMIRv2013.html. Accessed on 25 June 2020.

2. McCorkle R, Pasacreta J, Tang ST. The silent killer: psychological issues in ovarian cancer. Holistic nursing practice. 2003;17(6):300-8.

3. Tingulstad S, Hagen B, Skjeldestad FE, Halvorsen T, Nustad K, Onsrud M. The risk-of-malignancy index to evaluate potential ovarian cancers in local hospitals. Obstetrics \& Gynecology. 1999;93(3):44852.

4. Zahra F. Pattern of benign ovarian cysts in Qatari women. Qatar medical journal. 2017;2016(2):17.

5. Rashmi KS, Patil SB. Clinicopathological study of ovarian tumours. Perspective of clinical research. 2016;4(3):27-31. 
6. Patel A, Patel P, Karena Z, Vyas K. A retrospective analytic study of clino-histopathological correlation of ovarian mass. International Journal of Reproduction, Contraception, Obstetrics and Gynaecology. 2016;5(11):3802-5.

7. Kanthikar SN, Dravid NV, Deore PN, Nikumbh DB, Suryawanshi KH. Clinico-histopathological analysis of neoplastic and non-neoplastic lesions of the ovary: a 3-year prospective study in Dhule, North Maharashtra, India. Journal of clinical and diagnostic research. 2014;8(8):FC04.

8. Cancer 2015; American cancer society. Available at: file://C:/Users/DRC453 1.PRI/AppData/Local/Tem p/cancer-facts-and-figures-2015.pdf. Accessed on on 25 June 2020.

9. Leeuwen FE, Klip H, Mooij TM, Swaluw AM, Lambalk CB, Kortman M, et al. Risk of borderline and invasive ovarian tumours after ovarian stimulation for in vitro fertilization in a large Dutch cohort. Human reproduction. 2011;26(12): 3456-65.

10. Richardson DL. ACOG commitee opinion summary. Obstet Gynecol. 2017;130:e146-9.

11. Wills V, Mathew R. A study on clinicohistopathological patterns of ovarian tumours.
International Journal of Reproduction, Contraception, Obstetrics and Gynaecology. 2017;5 (8):2666-71.

12. Deeba F, Khatun S, Alam MM, Shahida SM. Serum LDH and CA-125: markers for diagnosis of ovarian malignancy. Mymensingh medical journal. 2015;24 (2):334-40.

13. Karimi-Zarchi M, Mojaver SP, Rouhi M, Hekmatimoghaddam SH, Moghaddam RN, YazdianAnari P, Teimoori S. Diagnostic value of the risk of malignancy index (RMI) for detection of pelvic malignancies compared with pathology. Electronic physician. 2015;7(7):1505.

14. Mamlouk MD, Shankar S, Silverman SG. Omental cakes: unusual aetiologies and CT appearances. Insights into imaging. 2011;2(4):399-408.

Cite this article as: Laul P, Miglani U, Srivstava A, Sood N, Miglani S. Correlation of clinical, biochemical and radiological characteristics with histopathology of ovarian masses: hospital based descriptive study. Int J Reprod Contracept Obstet Gynecol 2020;9:4449-54. 